\title{
Alzheimer's Disease and Alzheimer's Disease-Related Dementias in Older African American and White Veterans
}

\author{
Yan Cheng ${ }^{\mathrm{a}, \mathrm{b}}$, Ali Ahmed ${ }^{\mathrm{a}, \mathrm{b}, \mathrm{c}}$, Edward Zamrini ${ }^{\mathrm{d}}$, Debby W. Tsuang ${ }^{\mathrm{e}, \mathrm{f}}$, Helen M. Sheriff ${ }^{\mathrm{a}, \mathrm{b}}$ \\ and Qing Zeng-Treitler ${ }^{\mathrm{a}, \mathrm{b}, *}$ \\ ${ }^{a}$ George Washington University Biomedical Informatics Center, Washington, DC, USA \\ ${ }^{\mathrm{b}}$ Washington DC VA Medical Center, Washington, DC, USA \\ ${ }^{\mathrm{c}}$ Georgetown University, Washington, DC, USA \\ ${ }^{\mathrm{d}}$ University of Utah, Salt Lake City, UT, USA \\ ${ }^{\mathrm{e}}$ Geriatric Research Education and Clinical Center, VA Puget Sound, Seattle, WA, USA \\ ${ }^{\mathrm{f}}$ University of Washington Department of Psychiatry and Behavioral Sciences, Seattle, WA, USA
}

Accepted 26 February 2020

\begin{abstract}
.
Background: Racial disparity in the epidemiology of Alzheimer's disease and Alzheimer's disease-related dementias (AD/ADRD) has been reported. However, less is known about this disparity among Veterans.

Objective: To estimate the racial disparity in AD/ADRD among the Veterans.

Methods: Of the 5,413,418 Veterans $\geq 65$ years receiving care at the Veterans Health Administration (1999-2016), 4,045,269 were free of prevalent AD/ADRD, schizophrenia, or bipolar disorder at baseline. Of these, 432,469 were African American. Race was self-identified and incident AD/ADRD during 20 (median 6.7) years of follow-up was ascertained using International Classification of Diseases codes.

Results: Patients had a mean age of $70.4( \pm 6.6)$ years and 97.8\% were men. Age-sex-adjusted incidence of AD/ADRD per 1,000 person-year was 19.3 and 10.8 for African American and white Veterans, respectively (age-sex-adjusted hazard ratio associated with African American race, 1.77; 95\% confidence interval, 1.75-1.79; $p<0.0001$ ). This association remained essentially unchanged after multivariable adjustment (hazard ratio, 1.67; 95\% confidence interval, 1.65-1.69; $p<0.0001$ ). Among the key baseline characteristics that were significant predictors of AD/ADRD in both races, stroke was a significantly stronger predictor among African Americans, and Hispanic ethnicity and depression among whites (p-value for all interaction, <0.0001).

Conclusion: The findings of a higher incidence of AD/ADRD among African American Veterans is consistent with the findings in the general population reported in the literature, although the overall incidence appears to be lower than that in the general population. Future studies need to examine this disparity in incidence as well as the between-race heterogeneity in AD/ADRD risk.
\end{abstract}

Keywords: dementia, health status disparities, incidence, race factors

\section{INTRODUCTION}

Alzheimer's disease and Alzheimer's diseaserelated dementias (AD/ADRD) have emerged as

\footnotetext{
${ }^{*}$ Correspondence to: Qing Zeng-Treitler, PhD, George Washington University, 2600 Virginia Ave NW, Room 506, Washington, DC 20037, USA. Tel.: +1 202994 0477; E-mail: zengq@gwu.edu.
}

an urgent public health crisis in the United States [1]. About 6 million Americans $\geq 65$ years old suffer from $A D / A D R D$, most of whom are $\geq 75$ years old [2]. AD/ADRD poses significant psychological, physical, and financial burden on patients and their families, and the annual cost of AD/ADRD care is estimated to be about $\$ 300$ billion [1-5]. It is 
estimated that the number of Americans $\geq 65$ years of age will double to 88 million and those $\geq 85$ years will triple to 19 million by 2050 , which would further increase suffering and cost $[1,6]$. To address these challenges, in 2011 the National Alzheimer's Project Act (NAPA) was enacted into law, which has established the National Alzheimer's Project with a goal to create and maintain an integrated national plan to prevent and treat AD/ADRD by $2025[1,5]$.

The prevalence and incidence of AD/ADRD in the general population have been reported to be higher for African Americans than for whites [7]. One of the goals of the National Alzheimer's Project is to decrease disparities in AD/ADRD for racial and ethnic minority populations that are at higher risk for AD/ADRD [8]. The racial and ethnic disparity in $\mathrm{AD} / \mathrm{ADRD}$ epidemiology has been attributed to biological and socio-cultural factors [9-12]. However, others have pointed out that chronic stress of racism and social inequality may also contribute to this disparity [13-16]. Studies have reported racial disparities in self-reported health and prevalence of chronic disease among Veterans [17-20]. However, only a limited number of studies have investigated racial disparity of AD/ADRD in US Veterans [21, 22]. The objective of our study was to determine the incidence of AD/ADRD among a national sample of African American and white Veterans, and to examine predictors of AD/ADRD overall as well as separately within these two populations.

\section{METHODS}

\section{Data source and study population}

This is a cohort study based on Veteran Health Administration (VHA)'s Corporate Data Warehouse (CDW) data available at the VA Informatics and Computing Infrastructure (VINCI) [23]. We restricted our study sample to African American and white Veterans aged $\geq 65$ years who regularly received care in the VHA healthcare system during 1999-2016 calendar years. Regular use of VHA service was defined as at least 1 hospitalization or 2 outpatient visits within 12 months before the index VHA encounter qualifying the Veteran's entry into this cohort. To be eligible to enter into the study cohort, Veterans had to meet the following inclusion criteria: 1) have at least one outpatient or inpatient encounter after attaining age $\geq 65$ years during January 1999 and December 2016; 2) be free of diagnoses of AD/ADRD before

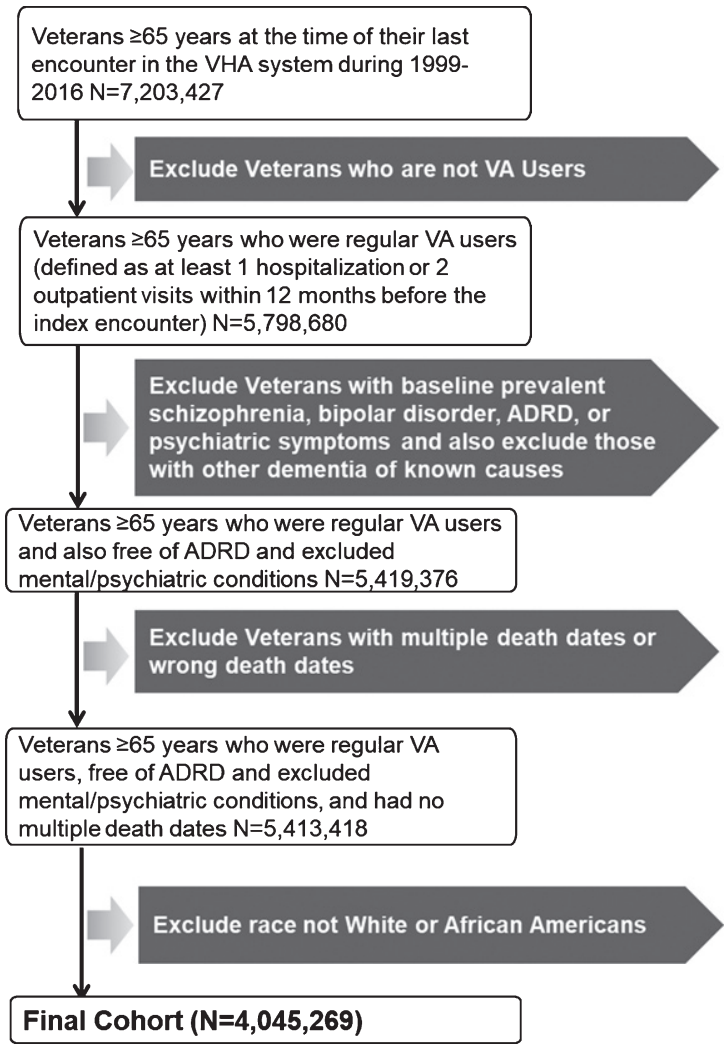

Fig. 1. Flow chart displaying assembly of Veteran cohort of AD/ADRD incidence study.

or at the index encounter; and (3) be free of severe psychiatric conditions, schizophrenia and bipolar disorder. A diagnosis of AD/ADRD was ascertained using International Classification of Diseases (ICD) codes (Supplementary Table 1). To establish the correct date of censoring, we excluded Veterans who had multiple death dates or wrong death dates (i.e., death date earlier than the last encounter date). We also excluded Veterans who had other dementia of known causes (ICD codes in Supplementary Table 2), because these are not AD/ADRD related dementia. Of the 7,203,427 Veterans aged $\geq 65$ years, 5,798,680 were regular VA users. After applying the inclusion/exclusion criterion, a total of 4,045,269 Veterans remained, including 432,469 African American and 3,612,800 white Veterans (Fig. 1).

\section{Race and other baseline characteristics}

The main exposure variable of the study was self-reported race, which was limited to African 
Table 1

Baseline characteristics of African American and white Veterans without AD/ADRD receiving care under the Veterans Health Administration Healthcare System (1999-2016)

\begin{tabular}{|c|c|c|c|c|}
\hline Number $(\%)$ or mean $( \pm$ SD) & $\begin{array}{c}\text { African } \\
\text { American } \\
(N=432,469)\end{array}$ & $\begin{array}{c}\text { White } \\
(N=3,612,800)\end{array}$ & $\begin{array}{c}\text { Absolute } \\
\text { standardized } \\
\text { difference }(\%)\end{array}$ & $p$ \\
\hline Baseline Age, years & $68.9( \pm 5.9)$ & $70.6( \pm 6.7)$ & 26.9 & $<0.0001$ \\
\hline \multicolumn{5}{|l|}{ Baseline Age Categories } \\
\hline $65-<70$ & $303,888(70.3 \%)$ & $2,088,604(57.8 \%)$ & 26.2 & $<0.0001$ \\
\hline $70-<75$ & $54,007(12.5 \%)$ & $558,994(15.5 \%)$ & 8.6 & $<0.0001$ \\
\hline $75-<80$ & $40,084(9.3 \%)$ & $495,168(13.7 \%)$ & 13.9 & $<0.0001$ \\
\hline $80-<85$ & $22,760(5.3 \%)$ & $309,041(8.5 \%)$ & 13.0 & $<0.0001$ \\
\hline $85+$ & $11,730(2.7 \%)$ & $160,993(4.5 \%)$ & 9.4 & $<0.0001$ \\
\hline Female & $11,746(2.7 \%)$ & $75,842(2.1 \%)$ & 4.0 & $<0.0001$ \\
\hline \multicolumn{5}{|l|}{ Ethnicity } \\
\hline Hispanic & $7,540(1.7 \%)$ & $139,623(3.9 \%)$ & 12.9 & $<0.0001$ \\
\hline Non-Hispanic & $412,259(95.3 \%)$ & $3,377,253(93.5 \%)$ & 8.0 & $<0.0001$ \\
\hline Unknown & $12,670(2.9 \%)$ & $95,925(2.7 \%)$ & 1.7 & $<0.0001$ \\
\hline \multicolumn{5}{|l|}{ Living Area Median Income } \\
\hline$\leq \$ 25,000$ & $21,806(5.0 \%)$ & $77,769(2.1 \%)$ & 15.6 & $<0.0001$ \\
\hline$\$ 25,001-50,000$ & $275,430(63.7 \%)$ & $1,857,303(51.4 \%)$ & 25.0 & $<0.0001$ \\
\hline$\$ 50,001-75,000$ & $113,912(26.3 \%)$ & $1,401,230(38.8 \%)$ & 26.8 & $<0.0001$ \\
\hline$>\$ 75,000$ & $15,040(3.5 \%)$ & $227,228(6.3 \%)$ & 13.1 & $<0.0001$ \\
\hline Unknown & $6,281(1.5 \%)$ & $49,271(1.4 \%)$ & 0.7 & $<0.0001$ \\
\hline \multicolumn{5}{|l|}{ Marital } \\
\hline Married & $209,645(48.5 \%)$ & $2,319,477(64.2 \%)$ & 32.1 & $<0.0001$ \\
\hline Single/Divorced/Widow & $221,766(51.3 \%)$ & $1,284,045(35.5 \%)$ & 32.1 & $<0.0001$ \\
\hline Unknown & $1,058(0.2 \%)$ & $9,279(0.3 \%)$ & 0.2 & 0.1333 \\
\hline \multicolumn{5}{|l|}{ Area } \\
\hline Urban & $354,323(81.9 \%)$ & $2,296,905(63.6 \%)$ & 42.1 & $<0.0001$ \\
\hline Rural & $42,234(9.8 \%)$ & $838,266(23.2 \%)$ & 36.8 & $<0.0001$ \\
\hline Unknown & $35,912(8.3 \%)$ & $477,630(13.2 \%)$ & 15.9 & $<0.0001$ \\
\hline Hypertension & $231,306(53.5 \%)$ & $1,374,942(38.1 \%)$ & 31.3 & $<0.0001$ \\
\hline Hyperlipidemia & $150,210(34.7 \%)$ & $1,203,809(33.3 \%)$ & 3.0 & $<0.0001$ \\
\hline Diabetes & $112,910(26.1 \%)$ & $634,986(17.6 \%)$ & 20.8 & $<0.0001$ \\
\hline Arthritis & $79,369(18.3 \%)$ & $459,094(12.7 \%)$ & 15.6 & $<0.0001$ \\
\hline Cancer & $45,142(10.4 \%)$ & $301,321(8.3 \%)$ & 7.2 & $<0.0001$ \\
\hline Ischemic Heart Disease & $48,889(11.3 \%)$ & $496,254(13.7 \%)$ & 7.3 & $<0.0001$ \\
\hline Depression & $66,395(15.4 \%)$ & $395,312(10.9 \%)$ & 13.1 & $<0.0001$ \\
\hline COPD & $28,721(6.6 \%)$ & $267,268(7.4 \%)$ & 3.0 & $<0.0001$ \\
\hline Anemia & $43,115(10.0 \%)$ & $136,519(3.8 \%)$ & 24.6 & $<0.0001$ \\
\hline Chronic Kidney Disease & $19,189(4.4 \%)$ & $54,352(1.5 \%)$ & 17.3 & $<0.0001$ \\
\hline Heart Failure & $17,816(4.1 \%)$ & $88,585(2.4 \%)$ & 9.4 & $<0.0001$ \\
\hline Stroke & $16,481(3.8 \%)$ & $84,061(2.3 \%)$ & 8.6 & $<0.0001$ \\
\hline Atrial Fibrillation & $8,274(1.9 \%)$ & $109,221(3.0 \%)$ & 7.1 & $<0.0001$ \\
\hline Asthma & $11,833(2.7 \%)$ & $71,210(2.0 \%)$ & 5.0 & $<0.0001$ \\
\hline Traumatic Brain Injury & $986(0.2 \%)$ & $5,655(0.2 \%)$ & 1.6 & $<0.0001$ \\
\hline \multicolumn{5}{|l|}{ Number of Comorbidities } \\
\hline $0-1$ & $217,400(50.3 \%)$ & $2,164,997(59.9 \%)$ & 19.5 & $<0.0001$ \\
\hline $2-3$ & $114,225(26.4 \%)$ & $877,444(24.3 \%)$ & 4.9 & $<0.0001$ \\
\hline $4-5$ & $69,864(16.1 \%)$ & $413,601(11.4 \%)$ & 13.7 & $<0.0001$ \\
\hline $6+$ & $30,980(7.2 \%)$ & $156,758(4.3 \%)$ & 12.1 & $<0.0001$ \\
\hline
\end{tabular}

Americans and whites. Patients with other races, and those who reported a mixed-race were excluded. Veterans with Hispanic ethnicity were included in both racial groups. Data on other baseline characteristics were obtained from the VHA data. Chronic comorbid conditions were confirmed using ICD 9 and 10 diagnostic codes, which was documented at least twice up to the date of the index encounter.

\section{Outcomes}

The outcome of the study was the incidence of AD/ADRD, which was identified using the ICD 9 and 10 codes listed in the Supplementary Table 1. The VHA transitioned from ICD9 to ICD10 on October 1, 2015; however, to maximize the sample size, we included both ICD 9 and 10 diagnostic 
codes. We applied direct mapping of these codes from readily available resources (http://www.icd10 codesearch.com). To prevent the misclassification of an AD/ADRD outcome, we required an AD/ADRD diagnostic code to be present at least two clinical encounters, with the first date of diagnosis set as the "event" date. Time to event was calculated from the baseline (index encounter) to the first diagnosis of AD/ADRD. Patients who did not develop $\mathrm{AD} / \mathrm{ADRD}$ were censored at death, last encounter date, or December 31, 2018, whichever occurred first.

\section{Statistical analyses}

For descriptive analyses, we compared baseline characteristics of African American and white Veterans using Student t-statistic and Chi-squared analyses as appropriate. Due to the large sample size of our study, even very small differences may become statistically significant. As such, we also calculated absolute standardized differences (ASDs) for each comparison [24]. The ASDs for categorical variables were calculated using the following formula: $\frac{\left|p_{A}-p_{W}\right| * 100}{\sqrt{\left(p_{A} /\left(1-p_{A}\right)+p_{W} /\left(1-p_{W}\right)\right) / 2}}$, where $p$ is the proportion of a specific observed value, $A$ stands for African Americans, and $W$ stands for whites. For continuous variables, the ASD was calculated as $\frac{\left|m_{A}-m_{W}\right| * 100}{\sqrt{\left(s_{A}^{2}+s_{W}^{2}\right) / 2}}$, where $m$ is the mean and, $s$ is the standard deviation, $A$ stands for African Americans, and $W$ stands for whites.

AD/ADRD incidence was estimated as cumulative proportion of patients who developed AD/ADRD during the follow-up. We also estimated incidence rate as number of patients who developed AD/ADRD divided by the sum of person-years during the followup. We calculated age-specific, sex-specific, age and sex adjusted, and multivariable adjusted incidence of $\mathrm{AD} / \mathrm{ADRD}$ for the both racial groups. Because the length of follow-up duration was various in the cohort and age changed with the follow-up, cumulative proportion was not appropriate for age-specific incidence; therefore, we estimated age-specific incidence rate only. The numerator of age-specific incidence rate was the sum of patients whose AD/ADRD onset age at the specific category of $65-<70,70-<75$, $75-<80,80-<85$, and 85 or above; the denominator was the sum person-years patients contributed to the corresponding age categories.

We then used Cox regression models to estimate hazard ratios (HRs) and confidence intervals (CIs) for incident AD/ADRD associated with the African American race. Proportional hazard assumption for the models was checked by examining log-minus$\log$ curves of the two racial groups. We used two models, first that adjusted for age and sex only, and then the second adjusted for age and sex as well as all other covariates presented in Table 1 . We used the models to develop survival plots for incident AD/ADRD by race. We then repeated the models separately within African American and white Veterans to identify significant independent predictors for incident AD/ADRD within each racial category and checked for interaction in the overall cohort. Again, due to the extremely large sample size, many interaction terms were statistically significant but the difference in HR estimates between the two groups were small. Therefore, for interactions to be meaningful, we also required a relative difference of HR estimates between the two groups to be $>10 \%$.

We also conducted a sensitivity analysis in which an AD/ADRD diagnostic code was required to be present at least in one clinical encounter. It was different from our primary analysis that required $\mathrm{AD} / \mathrm{ADRD}$ diagnoses to be present for at least two clinical encounters. In the sensitivity analysis, all other variables were kept the same as those used in the primary analyses.

\section{Data availability statement}

The data that we used for the study cannot be shared per VHA policies. Procedures for data access and approval of requests by the VHA researchers are available on the VA Informatics and Computing Infrastructure website (https://www.hsrd. research.va.gov/for_researchers/vinci/default.cfm)

\section{RESULTS}

\section{Baseline characteristics}

The 432,469 African American and 3,612,800 white Veterans had a mean age of $70.4 \pm 6.6$ years old, and $97.8 \%$ were men. Compared to whites, African Americans were younger, lived in areas of lower income, and were less likely to be married and to live in rural areas (Table 1). African Americans also had more medical comorbidities than whites, especially for hypertension, diabetes, arthritis, depression, anemia, and chronic kidney disease. 
Table 2

AD/ADRD incidence rates for African American and white Veterans receiving care under the Veterans Health Administration Healthcare System (1999-2016), by age at AD/ADRD onset and sex

\begin{tabular}{|c|c|c|c|c|}
\hline & \multicolumn{2}{|c|}{$\begin{array}{c}\text { African American Veterans } \\
(N=432,469)\end{array}$} & \multicolumn{2}{|r|}{$\begin{array}{l}\text { White Veterans } \\
(N=3,612,800)\end{array}$} \\
\hline & $\%$ & $\begin{array}{l}\text { Incidence (per 1,000 } \\
\text { person-years) }\end{array}$ & $\%$ & $\begin{array}{c}\text { Incidence (per } \\
1,000 \text { person-years) }\end{array}$ \\
\hline \multicolumn{5}{|c|}{ AD/ADRD onset Age (y) } \\
\hline $65-<70$ & N.A. & 5.3 & N.A. & 3.2 \\
\hline $70-<75$ & N.A. & 9.4 & N.A. & 5.5 \\
\hline $75-<80$ & N.A. & 18.7 & N.A. & 10.7 \\
\hline $80-<85$ & N.A. & 32.0 & N.A. & 17.9 \\
\hline $85+$ & N.A. & 53.8 & N.A. & 28.4 \\
\hline \multicolumn{5}{|l|}{ Gender } \\
\hline Male & 11.5 & 16.1 & 8.3 & 10.9 \\
\hline Female & 6.0 & 11.2 & 9.0 & 13.6 \\
\hline
\end{tabular}

Table 3

Adjusted AD/ADRD incidence comparison between two races

\begin{tabular}{|c|c|c|c|c|c|}
\hline & \multirow{3}{*}{\multicolumn{2}{|c|}{$\begin{array}{c}\text { African Americans } \\
(N=432,469)\end{array}$}} & \multirow{3}{*}{\multicolumn{2}{|c|}{$\begin{array}{c}\text { Whites } \\
(N=3,612,800) \\
\text { Incidence of } \\
\text { AD/ADRD }\end{array}$}} & \multirow{4}{*}{$\begin{array}{c}\text { Hazard ratio }(95 \% \\
\text { confidence interval) } \\
\text { associated with African } \\
\text { American race }\end{array}$} \\
\hline & & & & & \\
\hline & & & & & \\
\hline & $\%$ & $\begin{array}{c}\text { Per 1,000 } \\
\text { person-years }\end{array}$ & $\%$ & $\begin{array}{c}\text { Per } 1,000 \\
\text { person-years }\end{array}$ & \\
\hline $\begin{array}{l}\text { Age and sex } \\
\text { adjusted }\end{array}$ & 13.4 & 19.3 & 8.2 & 10.8 & $1.77(1.75-1.79) ; p<0.0001$ \\
\hline $\begin{array}{l}\text { Multivariable- } \\
\text { adjusted* }\end{array}$ & 12.5 & 17.6 & 8.2 & 10.8 & $1.67(1.65-1.69) ; p<0.0001$ \\
\hline
\end{tabular}

*Model adjusted for age, sex, race, ethnicity, income, marital status, area, all individual comorbid conditions.

\section{African American race and incident AD/ADRD}

A total of 49,082 African American Veterans and 300,372 white Veterans developed AD/ADRD. For African American Veterans, the most common $\mathrm{AD} / \mathrm{ADRD}$ diagnoses were nonspecific dementias $(43.5 \%)$, followed by unspecified dementias without behavioral disturbance (10.8\%), vascular dementias, uncomplicated (8.2\%), AD (6.7\%), and senile dementia, uncomplicated (5.1\%). In contrast, for white Veterans, they were other persistent mental disorders due to conditions classified elsewhere (43.3\%), unspecified dementias without behavioral disturbance (10.1\%), $\mathrm{AD}(9.6 \%)$, vascular dementias, uncomplicated (5.6\%), dementia unspecified (5.2\%), and senile dementia uncomplicated (5.2\%).

Incident AD/ADRD occurred in African American Veterans (11.5\% for males and $6.0 \%$ for females) and white Veterans (8.3\% for males and $9.0 \%$ for females) during about 20 years (mean of 7.0 years, median of 6.7 years) of follow-up (age and sex-adjusted HR, 1.67; 95\% CI, 1.65-1.69; $p<0.0001$; Tables $2-3$ and Fig. 2). This association remained unchanged after adjusting for the other covariates (Table 3). We observed a dose-response relationship between age and incidence rate, with the rate changing from 5.3 to 53.8 per 1,000 person-years in African Veterans and from 3.2 to 28.4 per 1,000 person-years in white Veterans (Table 2). Regardless of age-categories, African American Veterans consistently had a higher incidence rate of AD/ADRD than white Veterans.

\section{Predictors of $A D / A D R D$, overall and by race}

Significant predictors of a higher risk of incident AD/ADRD included age, not being married, the following medical comorbid conditions: including atrial fibrillation, anemia, chronic kidney disease, COPD, depression, diabetes, heart failure, ischemic heart disease, stroke, and traumatic brain injury (TBI; Table 4). Significant predictors of incident $\mathrm{AD} / \mathrm{ADRD}$ for the overall cohort were generally also significant within each racial group; however, the direction of the effect and magnitude of some of the predictors were different between the two groups, including sex, ethnicity, living area, the presence of arthritis, depression, and stroke (Table 5). 


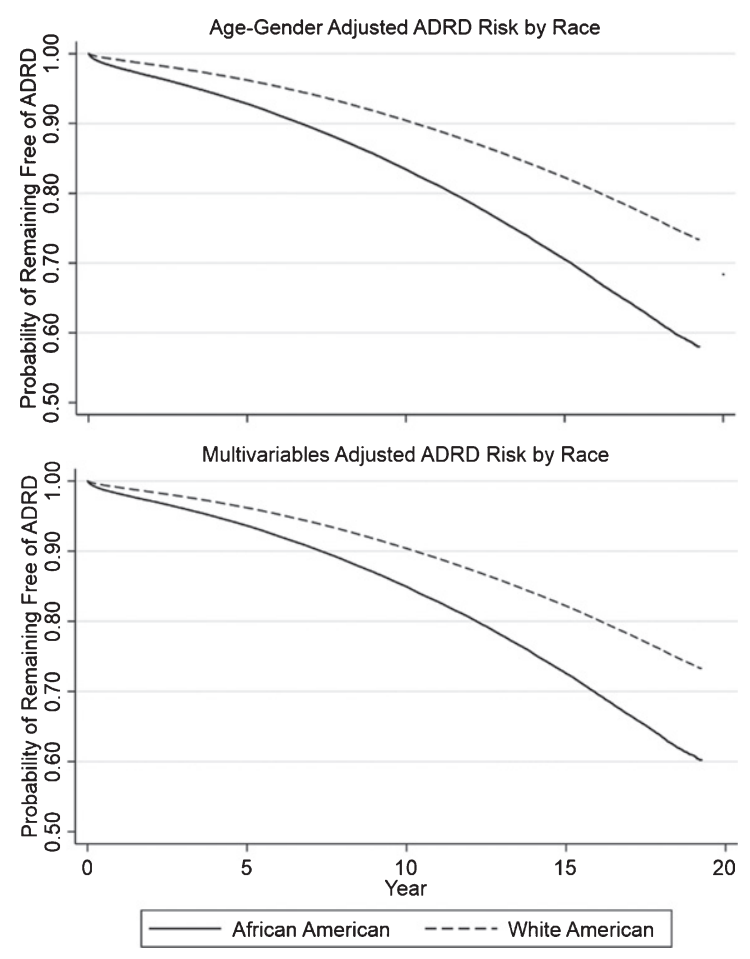

Fig. 2. Survival curves of AD/ADRD risk between two races.

Table 4

Predictors of AD/ADRD risk in the study cohort

\begin{tabular}{lcc}
\hline & Adjusted HR & $95 \%$ CI \\
\hline African Americans versus White & 1.67 & $1.65-1.69$ \\
Americans & & \\
Baseline Age & 1.10 & $1.10-1.10$ \\
Female versus Male & 1.02 & $0.99-1.04$ \\
Hispanic versus Non-Hispanic & 1.41 & $1.39-1.44$ \\
Living Area Median Income & & \\
$\quad 1^{\text {st }}$ Quartile (lowest) & Reference & - \\
$2^{\text {nd }}$ Quartile (lower) & 0.99 & $0.98-1.00$ \\
$3^{\text {rd }}$ Quartile (higher) & 0.97 & $0.97-0.98$ \\
$\quad 4^{\text {th }}$ Quartile (highest) & 0.90 & $0.89-0.91$ \\
Single/Widow/Divorced versus & 1.10 & $1.09-1.11$ \\
Married & & \\
Rural versus Urban & 0.91 & $0.90-0.92$ \\
Atrial Fibrillation & 1.10 & $1.07-1.13$ \\
Anemia & 1.17 & $1.15-1.20$ \\
Arthritis & 0.95 & $0.94-0.96$ \\
Asthma & 0.80 & $0.77-0.83$ \\
Cancer & 0.93 & $0.92-0.95$ \\
Chronic Kidney Disease & 1.27 & $1.22-1.31$ \\
COPD & 1.09 & $1.07-1.11$ \\
Depression & 1.65 & $1.63-1.68$ \\
Diabetes & 1.21 & $1.20-1.22$ \\
Heart Failure & 1.25 & $1.22-1.29$ \\
Hypertension & 0.87 & $0.86-0.88$ \\
Hyperlipidemia & 0.74 & $0.73-0.75$ \\
Ischemic Heart Disease & 1.05 & $1.04-1.06$ \\
Stroke & 2.09 & $2.04-2.14$ \\
Traumatic Brain Injury & 2.37 & $2.17-2.58$ \\
\hline
\end{tabular}

The association of sex and incident AD/ADRD varied between the races: HRs (95\% CIs) of incident AD/ADRD was $0.87(0.81-0.94)$ and 1.04 (1.02-1.07) for African Americans and whites, respectively ( $\mathrm{p}$ for interaction $<0.0001$; Table 5). Hispanic ethnicity, depression, and stroke were associated with a higher risk of AD/ADRD in both races, but the risk was significantly higher among African Americans. HRs (95\% CIs) for incident AD/ADRD among whites versus African Americans for Hispanic ethnicity, depression, and stroke were 1.15 versus 1.42 ( $\mathrm{p}$ for interaction<0.0001), 1.31 versus 1.73 ( $\mathrm{p}$ for interaction $<0.0001$ ), and 2.55 versus 1.98 ( $\mathrm{p}$ for interaction $<0.0001$ ), respectively. Living in rural area and having arthritis were associated with lower risk of AD/ADRD in both racial groups, but their HR estimates indicated stronger effect size among African Americans than whites with value of 0.75 versus 0.93 ( $\mathrm{p}$ for interaction $<0.0001$ ) and 0.83 versus 0.98 ( $\mathrm{p}$ for interaction $<0.0001$ ), respectively (Table 5).

\section{DISCUSSION}

Findings from our study demonstrate that the overall incidence of AD/ADRD was low among older US Veterans receiving care at the VHA compared to that of the general population $[25,26]$ and that the incidence of AD/ADRD was higher among African American than among white Veterans. We also observed that independent predictors of incident AD/ADRD were similar between the two races. However, there were between-race differences in the magnitude of some of these associations. To the best of our knowledge, this is the first report of racial disparity and race-specific predictors of the incidence of AD/ADRD in a national cohort of Veterans.

One possible explanation of the lower overall estimate of AD/ADRD in our study is that AD/ADRD is under-diagnosed or under-documented in the VA system [27]. Another possible explanation is that Veterans have a lower risk of AD/ADRD due to intense physical exercise during early military years and a more disciplined lifestyle thereafter [28]. However, the finding of a higher risk of AD/ADRD among African American Veterans is consistent with previous reports [25, 26, 29-33]. Age is an important predictor of AD/ADRD. However, African Americans in our study had a lower mean age that was both statistically significant $(p<0.0001)$ and substantial (ASD, 26.9\%) with potential for consequential bias. 
Table 5

Predictors of AD/ADRD by race

\begin{tabular}{|c|c|c|c|c|}
\hline & \multicolumn{2}{|c|}{ African Americans } & \multicolumn{2}{|c|}{ White Americans } \\
\hline & Adjusted HR & $95 \% \mathrm{CI}$ & Adjusted HR & $95 \% \mathrm{CI}$ \\
\hline Baseline Age & 1.11 & $1.11-1.11$ & 1.10 & $1.10-1.10$ \\
\hline Female versus Male* & 0.87 & $0.81-0.94$ & 1.04 & $1.02-1.07$ \\
\hline Hispanic versus Non-Hispanic* & 1.15 & $1.07-1.24$ & 1.42 & $1.40-1.45$ \\
\hline \multicolumn{5}{|l|}{ Living Area Median Income } \\
\hline $1^{\text {st }}$ Quartile (lowest) & Reference & - & Reference & - \\
\hline $2^{\text {nd }}$ Quartile (lower) & 1.02 & $0.99-1.05$ & 0.99 & $0.98-0.99$ \\
\hline $3^{\text {rd }}$ Quartile (higher) & 1.01 & $0.98-1.03$ & 0.97 & $0.96-0.98$ \\
\hline $4^{\text {th }}$ Quartile (highest) & 0.96 & $0.94-0.99$ & 0.90 & $0.89-0.91$ \\
\hline Single/Widow/Divorced versus Married & 1.04 & $1.02-1.06$ & 1.11 & $1.10-1.12$ \\
\hline Rural versus Urban* & 0.75 & $0.72-0.77$ & 0.93 & $0.92-0.94$ \\
\hline Atrial Fibrillation & 1.08 & $0.99-1.18$ & 1.10 & $1.08-1.13$ \\
\hline Anemia & 1.17 & $1.07-1.17$ & 1.22 & $1.19-1.26$ \\
\hline Arthritis* & 0.83 & $0.80-0.86$ & 0.98 & $0.96-0.99$ \\
\hline Asthma & 0.78 & $0.72-0.86$ & 0.81 & $0.77-0.84$ \\
\hline Cancer & 0.90 & $0.86-0.94$ & 0.94 & $0.92-0.96$ \\
\hline Chronic Kidney Disease & 1.34 & $1.25-1.43$ & 1.27 & $1.21-1.32$ \\
\hline COPD & 1.05 & $0.99-1.11$ & 1.09 & $1.07-1.11$ \\
\hline Depression* & 1.31 & $1.25-1.36$ & 1.73 & $1.70-1.75$ \\
\hline Diabetes & 1.15 & $1.12-1.18$ & 1.22 & $1.21-1.24$ \\
\hline Heart Failure & 1.27 & $1.19-1.35$ & 1.24 & $1.21-1.28$ \\
\hline Hypertension & 0.90 & $0.88-0.92$ & 0.87 & $0.86-0.87$ \\
\hline Hyperlipidemia & 0.74 & $0.71-0.76$ & 0.74 & $0.73-0.75$ \\
\hline Ischemic Heart Disease & 1.11 & $1.07-1.16$ & 1.04 & $1.03-1.06$ \\
\hline Stroke* & 2.55 & $2.43-2.67$ & 1.98 & $1.93-2.03$ \\
\hline Traumatic Brain Injury & 2.49 & $2.06-3.02$ & 2.32 & $2.11-2.56$ \\
\hline
\end{tabular}

* $p$-value for interaction $<0.0001$ and HR relative difference between two racial groups $>10 \%$.

Yet, despite their lower mean age, African American Veterans had a higher risk of AD/ADRD. One potential explanation is the between-group difference in baseline distribution of AD/ADRD risk factors. For example, diabetes mellitus (DM) is a major risk factor for AD/ADRD [34] and also significantly increased the risk of AD/ADRD by $21 \%$ in our study. The prevalence of DM was about 50\% higher among African Americans with an ASD of $20.8 \%$ which suggests that it had the potential to contribute to the higher risk of AD/ADRD among African Americans. Although we adjusted for the prevalence of DM in our regression model, it may not account for severity of DM at baseline or during followup. If DM was severe or progressed faster among African Americans, then that may in part explain their higher risk of AD/ADRD. Baseline stroke and TBI increased the risk of AD/ADRD by $109 \%$ and $137 \%$, respectively, in our study. The prevalence of both conditions at baseline were significantly higher among African Americans. However, ASD for both conditions were $<10 \%$ suggesting that any confounding by the variables were likely inconsequential.

Another potential explanation of a higher risk of $\mathrm{AD} / \mathrm{ADRD}$ among African American Veterans is racial discrimination. A recent study based on 368
African Americans with usable gene expression data from the Family and Community Health Study computed accelerated aging as well as self-reports of racial discrimination (Schedule of Racist Events) and depression (Diagnostic Interview Schedule for Children-Version 4) [14]. In that study, racial discrimination at ages 10-15 was associated with depression at ages 20-29 years, which in turn was associated with accelerated cellular-level aging. Thus, it is possible that cumulative life stress due to racial discrimination during early and adult life may increase the risk of $\mathrm{AD} / \mathrm{ADRD}$ at an earlier age via accelerated aging. However, our study, in which race was self-reported race, was not designed to examine the role of racial discrimination as a potential underlying mechanism of racial disparities in $\mathrm{AD} / \mathrm{ADRD}$ risk.

Although we did not have data on income at an individual level, higher quartiles of median income of living area was associated with a lower risk of $\mathrm{AD} / \mathrm{ADRD}$. This in part be explained by a higher education level and healthier lifestyle that are associated with higher income. Interestingly, this association was only observed among whites, and not among African Americans. One potential explanation of this may be that the gaps between quartiles of income among African Americans were not sufficiently large 
enough to impact mediators that maybe associated with a lower risk of AD/ADRD. Female sex is a known risk factor for AD/ADRD. However, we found no overall association between sex and incident AD/ADRD. The modest $4 \%$ higher risk among whites was likely cancelled by the robust $13 \%$ lower risk among African Americans. The opposing direction of this association is intriguing and needs to be replicated in future studies. We observed that being married and rural residence were associated with a lower risk of AD/ADRD, which are consistent with previous findings $[35,36]$. Hypertension is an established risk factor for AD/ADRD, and inverse association observed in our study is intriguing. However, higher blood pressure has been shown to have paradoxical relationships with better outcomes in the presence of other morbidities such as heart failure [37, 38]. Brain injury including TBI and stroke and psychiatric disorders such as depression are strongly associated with the increased risk of developing AD/ADRD. These findings are consistent with what was reported in published systematic reviews and meta-analyses.

Our study has clinical and public health implications. To the best of our knowledge, this is the first study to examine racial disparity in AD/ADRD incidence among a national cohort of US Veterans. Our findings also point to differences in the risk factors between older African American and white Veterans. Our findings identified several race-specific potentially modifiable risk factors. Future studies that replicate and confirm our findings are necessary.

Our study has several limitations. First, it was based on the Veteran populations, which is predominantly male that therefore limits generalizability. Second, we used diagnostic codes based on structured data to define AD/ADRD, which may have underestimated true incidence [22, 39, 40]. Third, we did not account for the severity of comorbid conditions, medications, or laboratory data. These additional factors should be further explored in future studies to fully understand the complex relationship between comorbid conditions and their association with incident AD/ADRD. Lastly, competing risk of death might be another limitation of our study. During the follow-up, 30.2\% African American and 35.5\% white Veterans died without developing AD/ADRD. Fine and Grey model or modified Poisson regression model may account for competing risk. However, due to the extremely large sample size, we did not have sufficient computational power to run the full models.

\section{Conclusion}

In a large national cohort of US Veterans aged $\geq 65$ years, African American race was associated with a higher risk of AD/ADRD when compared with whites. While both races shared the majority of the risk factors, important differences in magnitude and direction were observed between races, which if replicated and confirmed, may generate hypotheses for interventions. Future studies are necessary to develop and test race-specific interventions to lower the burden of AD/ADRD.

\section{ACKNOWLEDGMENTS}

The authors thank the US Department of Veteran Affairs for providing data and analytical software support. This work was supported by the grants including NIH 1UL1TR001876-01, VA I01 HX001145-02, and NIH R56 AG059739-01.

The content is solely the responsibility of the authors and does not necessarily represent the official views of the Veterans Health Administration.

Authors' disclosures available online (https:// www.j-alz.com/manuscript-disclosures/19-1188r2).

\section{SUPPLEMENTARY MATERIAL}

The supplementary material is available in the electronic version of this article: https://dx.doi.org/10. 3233/JAD-191188.

\section{REFERENCES}

[1] Assistant Secretary for Planning and Evaluation (ASPE) National Plan to Address Alzheimer's Disease: 2018 Update. Department of Health and Human Services, Washington, D.C. https://aspe.hhs.gov/system/files/pdf/259581/ NatPlan2018.pdf

[2] Gaugler J, James B, Johnson T, Marin A, Weuve J, Assoc As (2019) 2019 Alzheimer's disease facts and figures. Alzheimers Dement 15, 321-387.

[3] Bateman RJ, Xiong C, Benzinger TL, Fagan AM, Goate A, Fox NC, Marcus DS, Cairns NJ, Xie X, Blazey TM, Holtzman DM, Santacruz A, Buckles V, Oliver A, Moulder K, Aisen PS, Ghetti B, Klunk WE, McDade E, Martins RN, Masters CL, Mayeux R, Ringman JM, Rossor MN, Schofield PR, Sperling RA, Salloway S, Morris JC, Dominantly Inherited Alzheimer Networ (2012) Clinical and biomarker changes in dominantly inherited Alzheimer's disease. $N$ Engl J Med 367, 795-804.

[4] Villemagne VL, Burnham S, Bourgeat P, Brown B, Ellis KA, Salvado O, Szoeke C, Macaulay SL, Martins R, Maruff P, Ames D, Rowe CC, Masters CL, Australian Imaging Biomarkers and Lifestyle (AIBL) Research Group (2013) Amyloid beta deposition, neurodegeneration, and cognitive 
decline in sporadic Alzheimer's disease: A prospective cohort study. Lancet Neurol 12, 357-367.

[5] Rajan KB, Weuve J, Barnes LL, Wilson RS, Evans DA (2019) Prevalence and incidence of clinically diagnosed Alzheimer's disease dementia from 1994 to 2012 in a population study. Alzheimers Dement 15, 1-7.

[6] Hebert LE, Weuve J, Scherr PA, Evans DA (2013) Alzheimer disease in the United States (2010-2050) estimated using the 2010 census. Neurology 80, 1778-1783.

[7] Ighodaro ET, Nelson PT, Kukull WA, Schmitt FA, Abner EL, Caban-Holt A, Bardach SH, Hord DC, Glover CM, Jicha GA, Van Eldik LJ, Byrd AX, Fernander A (2017) Challenges and considerations related to studying dementia in Blacks/African Americans. J Alzheimers Dis 60, 1-10.

[8] National Plan to Address Alzheimer's Disease: 2018 Update,U.S. Department of Health \& Human Services, https://aspe.hhs.gov/report/national-plan-address-alzheime rs-disease-2018-update.

[9] Chin AL, Negash S, Hamilton R (2011) Diversity and disparity in dementia: The impact of ethnoracial differences in Alzheimer disease. Alzheimer Dis Assoc Disord 25, 187195.

[10] Lepore M, Lines L, Wiener J (2017) Alzheimer's disease and related dementias: Prevalence and racial and ethnic disparities in the United States. Generations Fall(Supplement), 22-29.

[11] Gilsanz P, Quesenberry CP, Jr., Mayeda ER, Glymour MM, Farias ST, Whitmer RA (2019) Stressors in midlife and risk of dementia: The role of race and education. Alzheimer Dis Assoc Disord 33, 200-205.

[12] Gilsanz P, Mayeda ER, Glymour MM, Quesenberry CP, Jr., Mungas D, DeCarli CS, Whitmer RA (2019) Birth in high infant mortality states and dementia risk in a cohort of elderly African American and White health care members. Alzheimer Dis Assoc Disord 33, 1-6.

[13] Chae DH, Nuru-Jeter AM, Adler NE, Brody GH, Lin J, Blackburn EH, Epel ES (2014) Discrimination, racial bias, and telomere length in African-American men. Am J Prev Med 46, 103-111.

[14] Carter SE, Ong ML, Simons RL, Gibbons FX, Lei MK, Beach SRH (2019) The effect of early discrimination on accelerated aging among African Americans. Health Psychol 38, 1010-1013.

[15] Jones CP (2000) Levels of racism: A theoretic framework and a gardener's tale. Am J Public Health 90, 1212-1215.

[16] Kim G, Sellbom M, Ford KL (2014) Race/ethnicity and measurement equivalence of the Everyday Discrimination Scale. Psychol Assess 26, 892-900.

[17] Sohn L, Harada ND (2008) Effects of racial/ethnic discrimination on the health status of minority veterans. Mil Med 173, 331-338.

[18] Harada ND, Damron-Rodriguez J, Villa VM, Washington DL, Dhanani S, Shon H, Chattopadhyay M, Fishbein H, Lee M, Makinodan T, Andersen R (2002) Veteran identity and race/ethnicity: Influences on VA outpatient care utilization. Med Care 40, I117-128.

[19] Washington DL, Harada ND, Villa VM, Damron-Rodriguez J, Dhanani S, Shon H, Makinodan T (2002) Racial variations in Department of Veterans Affairs ambulatory care use and unmet health care needs. Mil Med 167, 235-241.

[20] Petersen LA, Normand SL, Druss BG, Rosenheck RA (2003) Process of care and outcome after acute myocardial infarction for patients with mental illness in the VA health care system: Are there disparities? Health Serv Res 38, 41-63.
[21] Bhattarai J, Oehlert ME, Multon KD, Sumerall SW (2019) Dementia and cognitive impairment among US Veterans with a history of MDD or PTSD: A retrospective cohort study based on sex and race. J Aging Health 31, 1398-1422.

[22] Krishnan LL, Petersen NJ, Snow AL, Cully JA, Schulz PE, Graham DP, Morgan RO, Braun U, Moffett ML, Yu HJ, Kunik ME (2005) Prevalence of dementia among Veterans Affairs medical care system users. Dement Geriatr Cogn Disord 20, 245-253.

[23] Velarde KE, Romesser JM, Johnson MR, Clegg DO, Efimova O, Oostema SJ, Scehnet JS, DuVall SL, Huang GD (2018) An initiative using informatics to facilitate clinical research planning and recruitment in the VA health care system. Contemp Clin Trials Commun 11, 107-112.

[24] Austin PC (2009) Using the standardized difference to compare the prevalence of a binary variable between two groups in observational research. Commun Stat Simul Comput 38, 1228-1234.

[25] Mayeda ER, Glymour MM, Quesenberry CP, Whitmer RA (2016) Inequalities in dementia incidence between six racial and ethnic groups over 14 years. Alzheimers Dement 12, 216-224.

[26] Weuve J, Barnes LL, Mendes de Leon CF, Rajan KB, Beck T, Aggarwal NT, Hebert LE, Bennett DA, Wilson RS, Evans DA (2018) Cognitive aging in black and white americans: Cognition, cognitive decline, and incidence of Alzheimer disease dementia. Epidemiology 29, 151-159.

[27] Connolly A, Gaehl E, Martin H, Morris J, Purandare N (2011) Underdiagnosis of dementia in primary care: Variations in the observed prevalence and comparisons to the expected prevalence. Aging Ment Health 15, 978-984.

[28] Jones LG, Sin MK, Hage FG, Kheirbek RE, Morgan CJ, Zile MR, Wu WC, Deedwania P, Fonarow GC, Aronow WS, Prabhu SD, Fletcher RD, Ahmed A, Allman RM (2015) Characteristics and outcomes of patients with advanced chronic systolic heart failure receiving care at the veterans affairs versus other hospitals insights from the Beta-blocker Evaluation of Survival Trial (BEST). Circ Heart Fail 8, 17-24.

[29] Green RC, Cupples LA, Go R, Benke KS, Edeki T, Griffith PA, Williams M, Hipps Y, Graff-Radford N, Bachman D, Farrer LA, Grp MS (2002) Risk of dementia among white and African American relatives of patients with Alzheimer disease. JAMA 287, 329-336.

[30] Froehlich TE, Bogardus ST, Inouye SK (2001) Dementia and race: Are there differences between African Americans and Caucasians? J Am Geriatr Soc 49, 477-484.

[31] Barnes LL, Bennett DA (2014) Alzheimer's disease in African Americans: Risk factors and challenges for the future. Health Aff (Millwood) 33, 580-586.

[32] Tang MX, Cross P, Andrews H, Jacobs DM, Small S, Bell K, Merchant C, Lantigua R, Costa R, Stern Y, Mayeux R (2001) Incidence of AD in African-Americans, Caribbean Hispanics, and Caucasians in northern Manhattan. Neurology 56, 49-56.

[33] Tang MX, Stern Y, Marder K, Bell K, Gurland B, Lantigua R, Andrews H, Feng L, Tycko B, Mayeux R (1998) The APOE-epsilon4 allele and the risk of Alzheimer disease among African Americans, whites, and Hispanics. JAMA 279, 751-755.

[34] Akomolafe A, Beiser A, Meigs JB, Au R, Green RC, Farrer LA, Wolf PA, Seshadri S (2006) Diabetes mellitus and risk of developing Alzheimer disease: Results from the Framingham Study. Arch Neurol 63, 1551-1555. 
[35] Sommerlad A, Ruegger J, Singh-Manoux A, Lewis G, Livingston G (2018) Marriage and risk of dementia: Systematic review and meta-analysis of observational studies. J Neurol Neurosurg Psychiatry 89, 231-238.

[36] Astell-Burt T, Feng XQ (2018) Is the risk of developing Alzheimer's disease really higher in rural areas? A multilevel longitudinal study of 261,669 Australians aged 45 years and older tracked over 11 years. Health Place 54, 132-137.

[37] Tsimploulis A, Faselis C, Kanonidis I, Rashba E, Singh S, Deedwania P, Panjrath G, Allman R, Fonarow G, Ahmed A (2019) Association of Atrial fibrillation and outcomes in older patients with heart failure with preserved and reduced ejection fraction (Hfpef and Hfref). J Am Coll Cardiol 73, 797-797.
[38] Arundel C, Lam PH, Gill GS, Patel S, Panjrath G, Faselis C, White M, Morgan CJ, Allman RM, Aronow WS, Singh SN, Fonarow GC, Ahmed A (2019) Systolic blood pressure and outcomes in patients with heart failure with reduced ejection fraction. J Am Coll Cardiol 73, 3054-3063.

[39] Shao YJ, Zeng QT, Chen KK, Shutes-David A, Thielke SM, Tsuang DW (2019) Detection of probable dementia cases in undiagnosed patients using structured and unstructured electronic health records. BMC Med Inform Decis Mak 19, 128.

[40] Butler D, Kowall NW, Lawler E, Michael Gaziano J, Driver JA (2012) Underuse of diagnostic codes for specific dementias in the Veterans Affairs New England healthcare system. $J$ Am Geriatr Soc 60, 910-915. 